\title{
Applying Rigor to Agile Research and Innovation Projects Guided by Product Development
}

\author{
Alberto Tejero ${ }^{1}$ and Gonzalo León ${ }^{1}$ \\ ${ }^{1}$ Center for Technology Innovation (CAIT), Universidad Politécnica de Madrid, \\ alberto.tejero@upm.es, gonzalo.leon@upm.es
}

\begin{abstract}
This article, as a main contribution, shows a new agile way to manage and monitor R\&I projects, by monitoring product development. In addition, a new way of calculating the rigor of this type of projects is presented using the "3D rigor method", based on obtaining the rigor measures of the product, process and reputation of the project researchers. Thanks to this new method, it is possible to know the rigor of an R\&I project at any time during its development, which enables its monitoring and management to adapt it to the interests and needs of each situation. On the one hand, this method is presented as a tool of great utility for new researchers, since it will allow them to guide the development of their R\&I project in an agile way, adjusted to the speed of the current times, while maintaining minimum levels of rigor and scientific quality. On the other hand, the method is highly recommended for all those organizations that promote and support the development of new R\&I projects, enabling them to mentor and guide the projects towards the achievement of specific objectives and viable projects.
\end{abstract}

KEYWORDS: Scientific Rigor, Research, Innovation, R\&l, Project Management, TRL, Reputation, 3D Rigor Method, TRL Canvas, Open Innovation. 


\section{INTRODUCTION}

Projects are as old as our civilization. More than 4000 years ago, around 2550 B.C., large projects were already managed, such as the construction of the Egyptian pyramids. A project is, definitely, "an individual or collaborative enterprise that is carefully planned to achieve a particular aim"1. This individual or collaborative initiative can be of the "research project" type, which in a very short way can be defined as "a scientific investigation, usually using scientific methods, to achieve defined objectives" ${ }^{2}$.

The vision that has been created in recent decades about project management is based on the idea of conceiving management as a process [1]. There are many models in the literature for the management of research and innovation projects (R\&I) [1]-[3]. However, research is embedded in uncertainty, as well as innovation [4], [5]. Therefore, a predefined process that can completely guide research and / or innovation seems difficult to define, if it wanted to do it in a rigorous and detailed way. More in times when we talk about open innovation, where the limits of the known "innovation funnel" are porous, diffuse and there seems to be no sequential process [2]. So much so, that some authors have presented works where they conclude that to date has not created an innovation process model capable of being generalizable [6], [7], adding doubts and questions about the proper functioning of each one of the most relevant models.

When what is intended is the management of R\&l projects, all the steps that will be necessary to conduct from a simple idea to a marketable final product that is successful, are not known a priori. The complete process, or rather the necessary steps to obtain the innovation, will be known at the end of the project and not at the beginning of it. That is why other approaches are needed that allow "flexibility" to the management of R\&I projects, while preserving a minimum of scientific rigor that ensures the credibility and validity of the project [8].

In the world of cooking, although recipes delimit the process of preparing dishes, the product is what sets the pace of the cooking process. The product is what dictates at all times if more water or salt is needed, more time in the pan, etc. Within each of the states to which the product is passing, there are different activities that allow its evolution. The activities can be conducted by a single chef or by a group of chefs. Depending on the experience of the chefs and, ultimately, on their reputation, the cooking process can be more or less guided by a recipe. However, what happens when what is being prepared is a new dish never created before? Here, although the complete process of preparing the dish may be unknown, most of the activities necessary for the preparation of each part of the dish are usually known and will also have to be guided or trusted in the expert hands of the chefs in charge of its creation.

By introducing the uncertainty that comes with the preparation of a new dish, where a recipe is not available, the product is the one that completely defines the evolution of the dish until its final achievement; what is known for sure is that the product will go through different states until the new dish, the final product, is obtained. For example, in the preparation of stuffed turkey, the different elements or sub-products that make up the dish will be initially prepared separately, that is: the clean turkey, the stuffing and the sauce. In a second state of the product, all the elements

\footnotetext{
${ }^{1}$ Project definition https://www.lexico.com/en/definition/project

${ }^{2}$ Research project definition http://dbpedia.org/ontology/ResearchProject
} 
will be arranged together before putting it in the oven. And, in a final state, we will get the turkey already baked and ready for consumption. Here it is important to specify that, although each dish is different (cooking stuffed turkey, a pasta dish, etc.), in all of them the product will go through different states until the final dish is obtained.

Saving the distances with the world of cooking in the preparation of new dishes, in the development of an R\&I project something very similar occurs, since the product also has the prominence, not knowing a priori the exact order, as well as all the activities that the entire process will entail (although the necessary activities to be applied in each state of the product for its treatment and evolution are known). Therefore, the product is that really guides the development of an R\&l project.

This article, as a main contribution, shows a new agile way to manage and monitor R\&I projects, by monitoring product development. In addition, a new way of calculating the rigor of this type of projects is presented using the "3D rigor method", based on obtaining the rigor measures of the product, process and reputation of the project researchers. Thanks to this new method, it is possible to know the rigor of an R\&I project at any time during its development, which enables its monitoring and management to adapt it to the interests and needs of each situation.

This paper has the following structure. After this introductory section, the article reviews the relevant literature in the second section. This is followed by the materials and methods in the third section. Finally, a concluding section outlines theoretical and practical implications.

\section{THEORY BACKGROUND}

\subsection{Research management complexity}

According to [9], "Research management can be described as boundary work that produces couplings between science and the wider society. Because of the complexity of organized science, management is increasingly indispensable to ensure the social, cognitive, and material preconditions of research".

In general, research management is seen as a complex social phenomenon, which implies complex processes where changes and challenges occur [10]. In fact, research projects are often more complex than initially perceived, due to the novelty, the creativity inherent in the design process, as well as the added complexity of the limited experience of novice researchers [11]. This complexity of research projects is often underestimated, resulting in a misalignment between the interceded parts of the project, as well as the delays that are consequently produced.

As [12] argue, given that the literature on research management is in an emerging stage, the importance of theories and methodologies from other disciplines can be seen as very promising paths.

\subsection{Innovation process uncertainty}

Innovation requires continuous monitoring of the factors that may affect its development, both external and internal. However, it is not easy, since innovation is a complex process, consisting of a 
set of technical, organizational, productive and commercial stages that lead to the successful launch of new manufactured products or new services to the market [13]. The nature of the characteristics and activities of this process can generate a lot of uncertainty within the innovation [4]. To emphasize the uncertain character of this innovation process, other authors use the innovation journey [14]. Therefore, a first recommendable step in managing innovation is to understand how the innovation process can be successfully influenced.

As it can be seen through the literature, innovation management has a clear focus on the process, where many studies and well-known authors have worked on this topic. So, [15] emphasized that "a core in innovation studies is the conceptualization of innovation as an interactive process involving many actors and extending over time". That is the reason why many authors try to develop new models capable of analyzing the innovation process and explain its functioning (although it is difficult to find a universal model capable of explaining and much less guiding a phenomenon as dynamic and unpredictable as is the process of innovation in organizations).

Therefore, to know the process is not a simple task, because innovation is a complex, diversified activity, with many interacting components that act as sources for new ideas, so it is very difficult to discover the consequences that a new event of this nature can cause and hence its uncertainty [5]. This seems to indicate that new approaches are needed that allow to shed some light on so much uncertainty.

\subsection{Scientific rigor}

Oxford defines rigor ${ }^{3}$ as "The fact of being careful and paying great attention to detail [academic/intellectual/scientific, etc.]". The word rigor is derived from an old French word, "rigueur," meaning strength and hardness ${ }^{4}$. Being more specific, at scientific level, scientific rigor ${ }^{5}$ is "the strict application of the scientific method to ensure robust and unbiased experimental design, methodology, analysis, interpretation and reporting of results". Emphasize how the experimental design and methods proposed will achieve robust and unbiased results.

Therefore, rigor is dissatisfaction with uncertainty, inaccurate answers and imprecise measurements. But above all, rigor is also being methodical commitment to experimental procedure, to the need of controlling all parameters that can affect the results of our tests [16].

The application of scientific rigor is important, because it provides projects with credibility, reliability and transferability [8]:

- Credibility is achieved when the study participants and others who have experienced the research phenomenon recognize the study findings as real or true.

- Confirmability relates to the neutrality of the data interpretation. Confirmability is achieved when other researcher or researchers can follow the original researcher's path and obtain similar findings.

- Transferability means to transfer the study findings to other groups or contexts.

\footnotetext{
${ }^{3}$ Rigor definition https://www.oxfordlearnersdictionaries.com/definition/english/rigour

${ }^{4}$ https://mbio.asm.org/content/7/6/e01902-16

${ }_{5}^{5}$ Scientific rigor definition https://www.ncbi.nlm.nih.gov/pmc/articles/PMC5862244/
} 


\subsection{Technology Readiness Levels (TRL) to systematically assess the technology maturity}

In the mid-1970s, the National Aeronautics and Space Administration (NASA) introduced the concept of "technology readiness levels" (TRLS) as a discipline-independent, programmatic figure of merit to allow more effective assessment of, and communication regarding the maturity of new technologies [17]. Since then, the TRL scale has been widely used by industry as well as by military or government organizations as relevant as NASA itself, the U.S. Department of Defense or the European Union.

According to [18], "Technology Readiness Levels (TRLs) are a systematic metric/measurement system that supports assessments of the maturity of a particular technology and the consistent comparison of maturity between different types of technology". In this regard, TRL is a commonly accepted tool to measure the degree of maturity of a technology.

There are nine levels that comprise the TRL scale, from the basic principles of a new technology, to successfully testing in a real environment, as shown in Figure 1.

Assessing Specific Technology "Functional Maturity"

Technology Readiness Levels (TRLs)

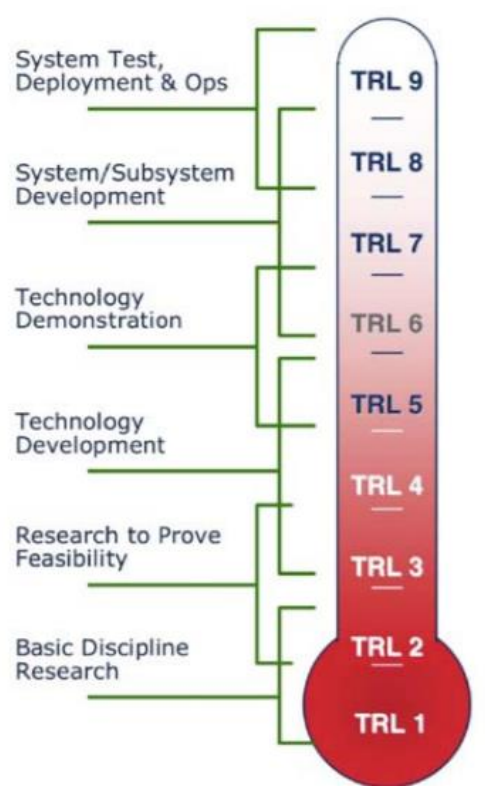

Actual system "proven" through successful system and/or mission operations

Actual system completed and :qualified" through test \& demonstration (in the operational environment

System prototype demonstration in the planned operational environment

System/subsystem model or prototype demonstration in a relevant environment (Ground or Space)

Component and/or breadboard validation in relevant environment

Component and/or breadboard validation in 'laboratory' environment

Analytical and experimental critical function and/or characteristic proof-of-concept

Technology concept and/or application formulated

Basic principles observed and reported

Figure 1. Overview of the technology readiness levels scale (Source: [17])

\section{MATERIALS AND METHODS}

\subsection{ELEMENTS FOR CALCULATION OF RIGOR}

Analyzing an R\&I project, three main elements can be identified: 1) the product, which evolves from a simple idea to obtaining a final product, 2 ) the process, which defines the activities necessary for 
the modification of the product in each phase or its status and its passage to the next one, and 3) the researchers, who work in the different activities of the process to achieve the final product. Each of these three elements can demarcate the rigor of a project.

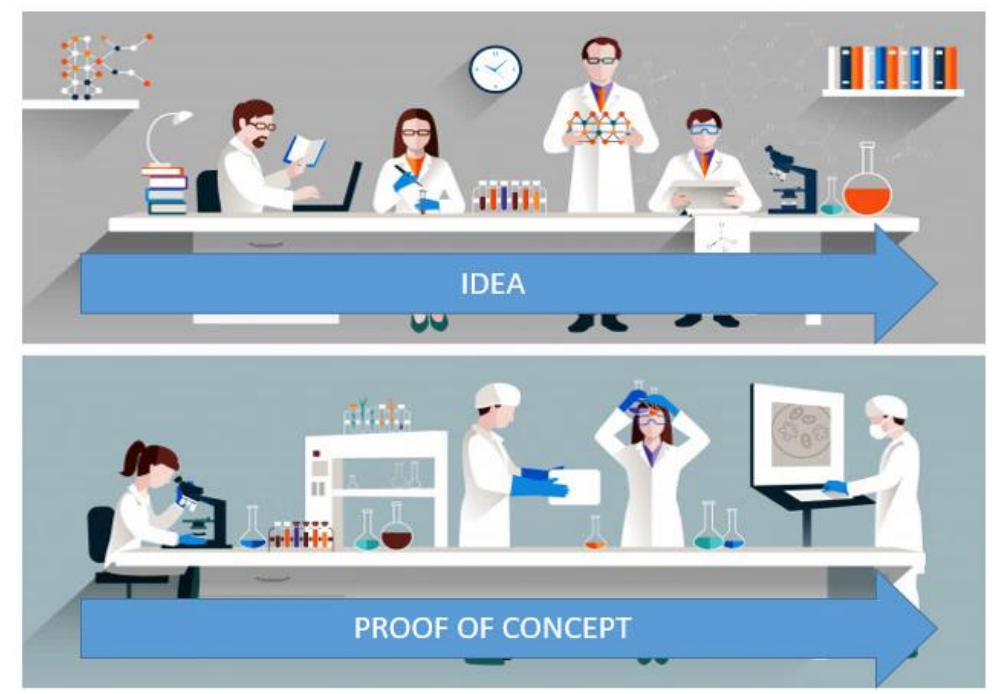

Figure 2. Main elements of an R\&I project: product, process and researchers (Source: own elaboration from Freepik.es ${ }^{6}$ )

The product, either by its very essence or motivated by the state in which it is, will require the application of greater or lesser rigor for its creation and evolution. For its part, the process, guided by the needs of the treated product, will entail the realization of a series of activities that may be more or less strict depending on the complexity of the activities themselves, but also on their impact on the product being treaty. Finally, but not least, the researchers, or rather their experience or reputation in relation to the product being developed and the activities involved in their process, will dictate the need to apply more or less rigor. All these elements in conjunction, product, process and reputation, allow the dimensions definition for obtaining the rigor of an R\&I project (see the conceptual representation of rigor in Figure 3).

${ }^{6}$ https://www.freepik.es/vector-gratis/cientificos-concepto-laboratorio 3924859.htm\#position=9 


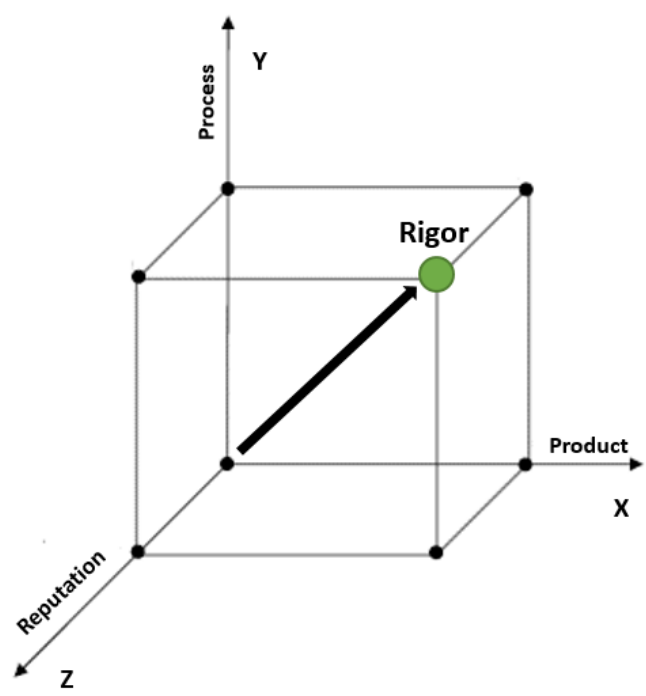

Figure 3. Conceptual representation of rigor by product, process and reputation dimensions (Source: own elaboration)

\subsubsection{Product}

As mentioned above, the evolution and development of an R\&l project is guided by the development of the product, through its passage through different stages or states during the life of the project. This is key to understanding the evolution of an R\&I project. In this sense, an R\&I project, in essence, is flexible or shares an agile approach, since the activities carried out in its development are conducted according to what the product requires at each moment of the project, not being predefined activities initially or immovable activities of a process delimited by stages.

The TRL scale was conceived as a method to obtain the level of maturity of a technology or product at a given time. Similarly, its use is also possible to show the different states through which an R\&l product passes from its conception as an idea and to its commercialization as a product, as shown in Figure 4. In this sense, TRL scale is presented as an invaluable tool for monitoring and management of R\&I projects.

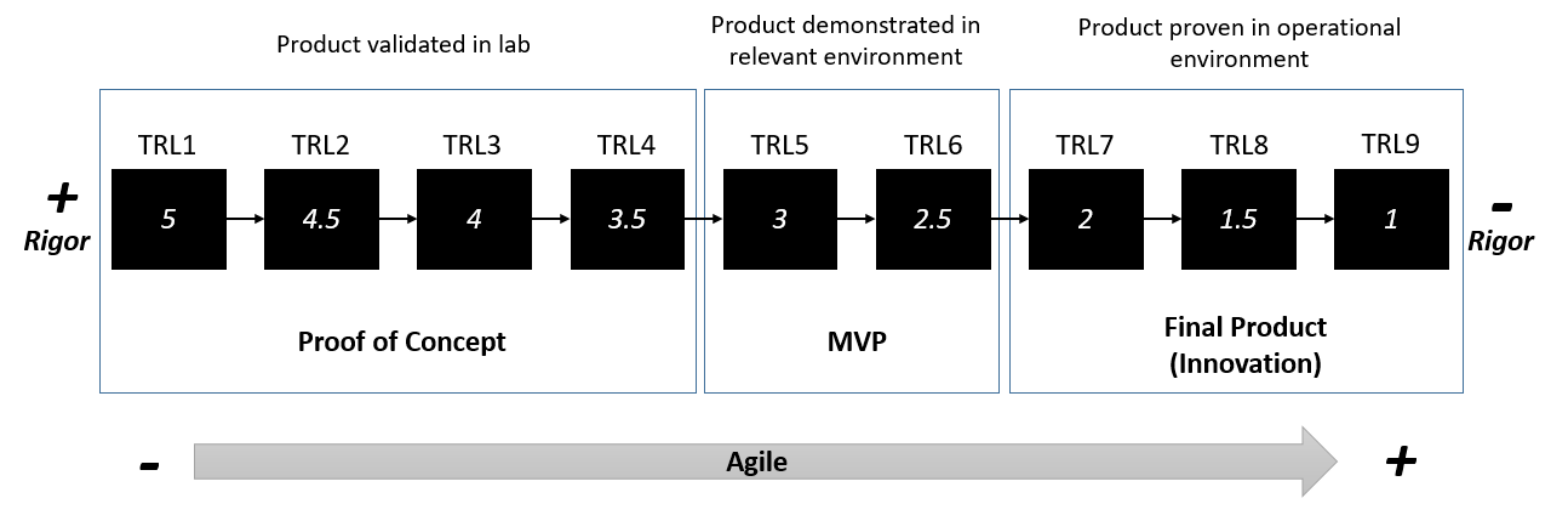

Figure 4. Products and rigor according to the levels of the TRL scale (Source: own elaboration) 
Figure 4 shows how the TRL scale can be used as a tool to show the different states in which the product of an R\&I project generally evolves, but also to establish an initial assessment of the rigor levels of the product of a project. In this way, at the lowest levels TRL 1-4, corresponding to the generation of the first prototype or "proof of concept" (PoC), the rigor is maximum, since they are the levels that correspond to the research phase most basic [19]. In the intermediate levels TRL 56 , corresponding to the generation of the "MVP"7, the levels of rigor are intermediate, since it works to obtain a product with sufficient characteristics to satisfy the initial customers, and provide feedback for the future development [20]. Finally, in the higher levels TRL 7-9, corresponding to the generation of the "final product" or innovation [19], the levels of rigor are minimal since when the project is in its most agile phase for the placing on the market and marketing of the final product. As can be seen, this approach fits with the agile methodologies approach, since it is precisely at the levels of greater maturity of the product where interaction and knowledge of the interests of users is more necessary, for the deployment and implementation of the final product.

Here it should be noted that, during the development of the project, intermediate products could be generated at each of the TRL levels, so that the rigor assessment can be reconfigured at different levels as the project evolves.

\subsubsection{Process}

The process of developing $R \& I$ projects involves the realization of very varied activities, as noted in section 2 of this document. This process can be more or less strict depending on various factors, the product being the one that, largely, defines the necessary activities to be conducted, depending on the state in which it is located and the necessary requirements for its evolution.

It could think that every R\&I project must have strict scientific rigor. This is partly true, since, although it is true that strict rigor is necessary, it is not so throughout the entire project development process. To begin, as noted in the previous section, the evolution of the project is guided by the product, so the activities involved in the process will be one or the other depending on the needs that the product may have at any time. That is why an $R \& I$ project shares certain characteristics, principles and values with agile methodologies (see in the previous Figure 4, how effectively the use of an agile approach increases as the product evolves).

From the TRL scale for the measurement of maturation of a project developed by NASA, the "Technology Readiness Calculator" tool was created by the US Department of Defense (DOD) ${ }^{8}$. The TRL Calculator is a tool for applying TRL to technology development programs. In its present form, the calculator is a Microsoft Excel spreadsheet application that allows the user to answer a series of questions about a technology project. Once the questions have been answered, the calculator displays the TRL achieved.

Using the set of questions established for the different TRL levels in the Technology Readiness Calculator tool, it is possible to define a first base of general activities to be conducted for each level. As an example, Table 1 shows some of these activities, for levels TRL1, TRL2 and TRL3.

\footnotetext{
${ }^{7}$ Minimum Viable Product

${ }^{8}$ Technology Readiness Calculator

https://ndiastorage.blob.core.usgovcloudapi.net/ndia/2003/systems/nolte2.pdf
} 


\begin{tabular}{|l|l|l|}
\hline \multicolumn{1}{|c|}{ TRL1 } & \multicolumn{1}{|c|}{ TRL2 } & \multicolumn{1}{c|}{ TRL3 } \\
\hline $\begin{array}{l}\text { Basic scientific principles } \\
\text { observed }\end{array}$ & Possible application exists & $\begin{array}{l}\text { Physical laboratory } \\
\text { experimental evidence } \\
\text { confirms basic principles }\end{array}$ \\
\hline $\begin{array}{l}\text { Paper studies confirm basic } \\
\text { principles }\end{array}$ & $\begin{array}{l}\text { Rigorous analytical studies } \\
\text { confirm basic principles }\end{array}$ & $\begin{array}{l}\text { Laboratory experiments verify } \\
\text { feasibility of application }\end{array}$ \\
\hline
\end{tabular}

Table 1. Example of initial set of activities for levels TRL1 to TRL3 (Source: own elaboration)

Of course, during the evolution of the project the set of activities can be expanded for each TRL level, as the product development requires. This fact demonstrates, once again that, although there is a rigor applied to the project, there is also a large degree of flexibility, typical of projects developed using agile methodologies.

Regarding the rigor of the process, this will be given by measuring the rigor of the different activities conducted in the nine TRL levels through which the project will pass. Thus, it will be possible to calculate not only the overall rigor of the process for the project, but also the rigor corresponding to each TRL level. These measures will be very useful to know the evolution of the project, causes and consequences of the changes produced in its development, but also for the comparison of projects and application of this knowledge in future implementations, etc.

The calculation of the rigor for each TRL level will be given by the application of a simple mathematical formula:

$$
\sum_{1}^{N} \frac{(\text { Activity } i * \text { Weight } i)}{N}
$$

As can be seen in the previous formula, each activity will have an associated weight. This is because not all activities to be conducted will have the same importance for the product development at each TRL level and its evolution to the next level. The research team will be responsible for assigning the different weights to the activities at each level, based on accepted standards or well-known assumptions in the specific field of research (something necessary not only for the evolution of the project itself, but also to enable comparison with others of the same type). On the other hand, the total value of project process rigor will be given by the average of the rigor values obtained at all TRL levels:

$$
\frac{\sum_{1}^{9}(T R L i)}{9}
$$

As for the values of rigor associated with the activities, these will be defined according to the reputation of the researchers involved in each activity (that is, they will be closely related to each other). Thus, the value of rigor by activity will be equal to the average of the values of rigor of the researchers participating in that activity: 


$$
\frac{\sum_{1}^{N}(\text { Researcher } i)}{N}
$$

Therefore, the application of more or less rigor at each TRL level will depend on the needs of the product in part, although it will also be largely conditioned by the experience or reputation of the researchers involved in the process.

\subsubsection{Reputation}

Going back to the analogy used at the beginning of this paper, in a professional cooking process, several chefs usually participate. The success of the preparation of each dish will depend many times on the experience, but also on the expertise (skills) of the chefs in each of the elaborations necessary to conclude a dish. Therefore, the reputation of the chefs plays a decisive role, determining if the process of creating the dish can be left in their expert hands, or it will be necessary for the process to be guided, if the chefs are inexperienced or lack sufficient reputation for their preparation.

In R\&I projects, something very similar to what happened in the world of professional cuisine occurs, where reputation also plays a decisive role, having a direct impact on the rigor of the project. In this case, the rigor applied to the researchers will be given by their reputation, so that each researcher will have an associated rigor value, obtained as an inverse function of his/her reputation:

$$
\text { Rigor of Researcher } \mathrm{i}=\frac{1}{\text { Reputation } i}
$$

Worth paying attention to when referring to researchers in open innovation contexts ${ }^{9}$, we may be referring not only to an individual researcher but also to a group, node or network. In each case, it will be necessary to calculate the value of their reputation, to later calculate the associated rigor for the project in which they participate. This approach to reputation within the new purposed model will then be taken into account below, in its description.

In the context of the 3D rigor model, presented above in this article, one of the dimensions concerns human resources (termed in the model as researchers or "people"). The model postulates that the way humans behave in one R\&I project (in each specific TR Level) conditions the "level of rigor" of the whole project.

This section will elaborate this dimension of rigor in relation to the "reputation of participating people" (both individual researchers and as components of research groups), and the relationship to the reputation of the entity where they belong to.

In the type of R\&I projects addressed in this article (i.e. those scientific projects where the results should be an innovation as a product/service hitting the market or society) the capacities and skills (both hard and soft) of people participating in projects (researchers and managers) constitute a key element for success. Many of the contributing factors are related to the people's adequacy in capacities and skills to fulfil the goals of the project to develop, and it should be measured for

\footnotetext{
${ }^{9}$ In an R\&I project in open innovation contexts, the tool for selecting partners can be a very interesting starting point for the calculation of a member's reputation [21].
} 
individuals or as a project team to generate some understanding of the level of trustability in the success.

Nevertheless, there is another soft concept that conditions "people rigor" dimension: the reputation they have, individually or as a research group, based on the past performance, behavior and external opinions about them in a given moment (later on, the reputation will be updated by external people through the direct knowledge of the way they work in a joint project and the consequences of their behavior in society).

Reputation is defined by Merriam Webster dictionary as: "a) overall quality or character as seen or judged by people in general or b) recognition by other people of some characteristic or ability". Furthermore, Cambridge dictionary defined reputation as: "the opinion that people in general have about someone or something, or how much respect or admiration someone or something receives, based on past behavior or character".

From both sources, the definitions of reputation refer to the identification of a "reputational object" (i.e. an external researcher or a group of them participating in the project where the assessment of reputation is relevant) and a "reputational evaluator" (i.e. the top level manager, project director, or external stakeholders like funding agencies if they exist, or society at large) independent from the reputational object, which gives a subjective opinion about the reputation of the object ${ }^{10}$.

In wider contexts, reputation is applied to entities and not individuals, which perceive the assessment of reputation as a risk: "Reputational risk is the potential loss to financial capital, social capital and/or market share resulting from damages to a firm's reputation. This is often measured in lost revenue, increased operating, capital or regulatory costs, or destruction of shareholder value $^{\prime 11}$. This issue is seriously considered by entities (both public and private) because branding value and social recognition depend on it.

Sometimes, as it happens in consortia-based projects and many other open innovation activities where several teams should work together, reputation should be assessed to external "partners" (legal entities participating in a project) and not only to individuals or research groups of the same entity (usually, they have not the legal structure to sign) to find the most appropriate one. In those cases, it became essential to deal with rigorous processes to measure reputation and to get the maximum level of agreement or consensus on the method used to avoid undesirable bias.

Roughly speaking, the participation of external partners with high levels of reputation increases the trustability in the success of the running open activities (both for participants and for funding agencies); therefore, high levels of reputation can generate smaller need of controlling the detail execution of project's tasks. On the other side, if reputation levels widely vary between persons or partners involved, or those levels are significatively low (i.e. below some thresholds), it is necessary

\footnotetext{
${ }^{10}$ This opinion could be requested as a part of a formal process of the assessment of reputation or it is given spontaneously (non-requested) by third parties for several reasons. This last process often occurs in social networks where the reputation of individuals or entities is continuously and publicly assessed with intended or unintended objectives, but with severe consequences in case of negative views. In this article, we only refer to formal assessment of reputation as a part of the analysis of the rigor dimension of people in R\&I projects.

${ }^{11}$ https://en.wikipedia.org/wiki/Reputational risk
} 
to set up full and close management control processes which implies the allocation of more resources and to fulfil additional monitoring activities.

Reputation, as presented above, is a soft qualitative concept strongly dependent on the quality of data and opinions used to assess the reputational level. In short, if the reputation level of one partner is based on scattered, unreliable or old data (i.e. not applicable to the situation found today), or it is based on not well-assessed and neutral opinions (even anonymous opinions in social networks), any decision based on reputation is biased. Then, a more precise implementation of reputation assessment schemes is needed.

The assessment of reputation is routinely done in research fields when it is linked to rewarding systems and funding allocation. Scholarly communication can be understood as "a communicative practice anchored in three dimensions: publicity, access, and trustworthiness" [22]. Recently, reputation has got another dimension linked to the used of social networks and Internet applications: it is linked to on-line opinions. Then, the on-line visibility of researchers is increasingly turning into something individual researchers have to consider and this has implications for how trust and reputation, which are both central to understanding the academic reward system, are shaped [23].

To apply the concept of reputation to R\&I projects, three "levels of reputation" are identified depending on the type of reputational object under consideration. These are:

1) "individual reputation" (of one researcher); usually, it is a key issue to identify potential participants or partners in R\&I projects. It is based on CV analysis, alignment of experience with new challenges, and external opinions on the performance and behavior of the researcher. Reputation level is used to start bilateral activities or to continue. The reputational evaluator in this case is the firm interested in hiring, selecting or contracting the researcher for specific $R \& \mid$ projects.

2) "research group reputation"; usually, research groups reputation in the academic sector depends on the leader and other key personnel reputation, but also on the capability to keep the group stable and able to incorporate additional talented people to cope with volume of work exceeding the individual one. When the concept is applied to firm's research groups, other elements appear like the alignment with the vision, priorities and strategy of the firm.

3) "firm (node) reputation"; usually, based on the reputation of all participating research groups and the performance of horizontal services of the firm supporting R\&I projects in global frameworks (e.g. in EU framework programs where some hints were defined based on 30 years of experience ${ }^{12}$ ).

\footnotetext{
12 "All partners need to be reliable and committed to the project and their obligations. Each partner should bring to the project excellent skills in a particular scientific field. When deliberating whether to choose partners from existing contacts or to approach new ones it is important to assess the following pros and cons. Existing contacts are likely most effective, most reliable and most predictable given a history of previous collaborations. However, past collaborators may at times be less suitable for a new project, especially when looking for complementary skills. New contacts may be a greater risk but may be a better option when looking for complementary skill sets in the different partners". https://euraxess.ec.europa.eu/worldwide/southkorea/how-find-european-partners-h2020-research-consortia
} 
Notice that these three levels of reputation are not fully independent, and the reputation at one level influences the reputation of the upper level by adding additional factors for consideration. Five factors were identified as the most relevant ones.

- The "experience" factor of reputation assessment measures the capability of the reputational object (i.e. researcher, research group, firm) to address the Science and Technology (S\&T) challenges of the R\&I project (or similar projects in the same domain). It should be based on the experience collected for the reputational object in the area (interest domain) under consideration, from public data and from unbiased opinions of firms or other stakeholders (e.g. funding agencies) cooperating with the object.

- The "role" factor of reputation measures the type of responsibility assumed by the reputational object in the R\&I project and its performance in the past to trust on it for future responsibilities of the same type. Notice that the reputation of one object could be very high in running projects, but not necessarily the same when playing the role of "coordinator". Then, apart from data, other qualitative opinions from trustable sources should be also considered at this level (and, if weighted, became quantitative inputs).

- The "cohesion" factor measures at what extent the components of a research group, or the interaction between research groups in a firm is reliable enough to address together some pre-defined S\&T challenges when complementarity of knowledge and experience is a must. This factor is strongly linked to the type of external partner (cohesion is higher in the case of private firms when top management can the power to reallocate people and work, and lower in the case of academic entities when academic freedom requires to convince other peers to participate in a R\&I project and academic authorities cannot intervene).

- The "coupling" factor measures the level of required interaction between research groups and firms to conduct some R\&I project. This level becomes relevant when partners should work together (e.g. as a consortium of entities); then, joint performance depends on the legal framework constraints (e.g. the consortium agreement and formal framework) and the will (based on cost-benefits analysis) to work together. In this case, the analysis of the reputation level implies to assume one or more of them (sometimes, one node is a good performer as executor of technical tasks in R\&I projects, but not necessarily as coordinator or evaluator of the R\&I project).

- The "social impact" factor measures the way that the (external) community assess the reputational value of the person, research group or firm in the way they contribute to society and is trustable. This factor is related to the positive "impact" and "influence" in society of the reputational object on the basis of past behavior; however, it should be understood in a wider context (not only technical and economic to deal with absence of disputes, capacity to conciliate, etc.).

Table 2 summarizes the factors affecting reputation in each of the identified reputation levels. 


\begin{tabular}{|c|c|c|c|c|c|}
\hline \multirow{2}{*}{$\begin{array}{c}\text { Reputational } \\
\text { levels }\end{array}$} & \multicolumn{5}{|c|}{ Factors affecting reputation } \\
\hline & Experience & Role & Cohesion & Coupling & Social impact \\
\hline Individual & $\begin{array}{l}\text { It is based on the } \\
\text { analysis of CV of } \\
\text { researchers in } \\
\text { relation to the area } \\
\text { of interest } \\
\text { (supported by } \\
\text { bibliometric } \\
\text { analysis), and } \\
\text { external opinions. }\end{array}$ & $\begin{array}{l}\text { Performance } \\
\text { and credibility } \\
\text { as researcher, } \\
\text { principal } \\
\text { investigator, or } \\
\text { coordinator for } \\
\text { an open } \\
\text { innovation } \\
\text { activity }\end{array}$ & $\begin{array}{l}\text { Not applicable at } \\
\text { individual level } \\
\text { (in some cases, } \\
\text { could be applied to } \\
\text { the coherence of } \\
\text { activities } \\
\text { performed by the } \\
\text { researcher in } \\
\text { his/her life). }\end{array}$ & $\begin{array}{l}\text { Integration in } \\
\text { entity's } \\
\text { mission, } \\
\text { vision and } \\
\text { culture. }\end{array}$ & $\begin{array}{l}\text { Based on the } \\
\text { community's } \\
\text { opinion on the } \\
\text { behavior of the } \\
\text { individual (i.e. } \\
\text { absence of } \\
\text { disputes, impact } \\
\text { and influence). }\end{array}$ \\
\hline $\begin{array}{l}\text { Research } \\
\text { group }\end{array}$ & $\begin{array}{l}\text { Activities of the } \\
\text { research group in } \\
\text { the last years in the } \\
\text { area of interest. }\end{array}$ & $\begin{array}{l}\text { Execution of an } \\
\text { open innovation } \\
\text { activity. }\end{array}$ & $\begin{array}{l}\text { Relationships } \\
\text { between members } \\
\text { of the research } \\
\text { group to work } \\
\text { together. Stability } \\
\text { of the group over } \\
\text { years }\end{array}$ & $\begin{array}{l}\text { Integration in } \\
\text { the R\&I } \\
\text { project. } \\
\text { Previous joint } \\
\text { participation } \\
\text { in similar } \\
\text { projects. }\end{array}$ & $\begin{array}{l}\text { Based in the } \\
\text { community's } \\
\text { opinion on the } \\
\text { behavior of the } \\
\text { research group } \\
\text { (i.e. absence of } \\
\text { disputes, impact } \\
\text { and influence). }\end{array}$ \\
\hline Node & $\begin{array}{l}\text { Average of the } \\
\text { reputation of all } \\
\text { research groups } \\
\text { participating in } \\
\text { open innovation } \\
\text { activities. }\end{array}$ & $\begin{array}{l}\text { Formal/legal } \\
\text { responsibility } \\
\text { for executing } \\
\text { the open } \\
\text { innovation } \\
\text { activity. }\end{array}$ & $\begin{array}{l}\text { Interaction } \\
\text { between research } \\
\text { groups to } \\
\text { complement the } \\
\text { necessary } \\
\text { knowledge for one } \\
\text { Ol activity. } \\
\text { Firm's trajectory. }\end{array}$ & $\begin{array}{l}\text { Interactions } \\
\text { between } \\
\text { research } \\
\text { groups in } \\
\text { different } \\
\text { nodes. }\end{array}$ & $\begin{array}{l}\text { Based in the } \\
\text { community's } \\
\text { opinion on the } \\
\text { behavior of the } \\
\text { firm (i.e. } \\
\text { absence of } \\
\text { disputes, impact } \\
\text { and influence). }\end{array}$ \\
\hline
\end{tabular}

Table 2. Relationships between factors and reputational levels (source: own elaboration)

The reputational level of the research group is essential in the most part of R\&I projects because, even if the research groups' leader has a very high reputational level from the academic point of view, the need to manage one ad hoc research group for a specific R\&I project implies to perform well in other levels very different.

The reputational level of the firm is always very relevant if $R \& \mid$ projects were launched and data collected (from the same firm or from others in the same domain) referred to its impact and influence is society.

Next logical step in the analysis of object reputation could be to assign (qualitatively) a value to each of them in specific contexts. In this way, theoretically, it would be possible to compare reputation values between researchers, research groups, nodes and networks, if necessary. Theoretically, if reputation in one level is "infinite", there is no need to allocate management resources to control the performance of external researchers or teams (once the R\&I project is granted), simply wait for the (good) results!! ${ }^{13}$

\footnotetext{
${ }^{13}$ Notice that this reputational scheme is used by many funding research agencies in some of their instruments for fundamental research. In those cases, the allocation of funds to very well-known and excellent researchers and "their" associated research groups (at least, up to a given amount) is granted based on past performance of the researchers in the field and not through a lengthy and costly evaluation of proposals. The message from the funding agency in these cases is very simple: go ahead! we trust on you based on your knowledge and reputation! In other cases, high-level reputation of some governmental entities can facilitate the allocation of funds by governments.
} 
Nevertheless, this process is mainly subjective, and it depends on the feeling and experience of the reputational evaluators (i.e. the experience in applying reputational measurements owned by the research group or firm) when performing the reputation analysis in any reputational level.

[24] have proposed a specific "metrics of reputation for individual researchers". It is based on the use of the following formulae where reputation is assessed in a number of categories (projects, publications, etc.):

$$
\operatorname{Rep}-\operatorname{Index}_{(\mathrm{R})}=\sum_{i=1}^{c}\left(\sum_{j=1}^{e_{i}} \frac{\left(v_{j} \cdot w_{j}\right)}{\max \left(v_{j}\right)}\right)
$$

- $\mathrm{R}$ : Refers to the researcher who wants to find out the reputation.

- c : Represents the total number of categories.

- $\quad \mathrm{i}$ : Represents the range of 1 up to the total number of categories (c).

- ei : Represents the total elements in each category.

- $j$ : Refers the range of 1 up to the total number of elements (ei).

- $v$ : Represents the value of the element.

- $\quad w j$ : Refers to the weight element.

- $\max (v j)$ : Represents the higher value of the element.

In the above formulae elements, values and weights are based on data based on quality metrics of publications (number of publications, citations, h-index, g-index, etc.) of the researcher where the scientific prestige is correlated to the "reputational level". Then, here the measurement approach is linked to bibliographic analysis.

Our position is that this approach does not capture the essential traits of reputation based on trustability for complex R\&I projects. It is relevant to consider other socio-technical variables. Furthermore, the analysis of the individual cannot be directly extrapolated to the research group, and even less to the entity.

Some open questions refer to the "time memory" window of the reputation data (i.e. how many years in the past should be considered to assess reputation ${ }^{14}$ ), the natural obsolescence of knowledge field that affects capacities, the stability of key personnel in the research group, etc. For all these reasons, assessment of reputation will remain a highly subjective process to be repeated dynamically over time.

Nevertheless, some efforts towards semi-quantitative assessment are possible. Table 3 refine Table 2 by providing elements towards semi-quantitative analysis of reputation ${ }^{15}$.

\footnotetext{
${ }^{14}$ It became a huge problem in Internet linked to rights to forget.

${ }^{15} \mathrm{~A}$ global figure of reputation level is not proposed. We prefer at this stage to manage individual factors and to rely on additional experience before proposing any synthetic (composed) indicator of reputation.
} 


\begin{tabular}{|c|c|c|c|c|c|c|c|c|c|c|c|}
\hline \multirow{3}{*}{$\begin{array}{c}\text { Reputation } \\
\text { levels }\end{array}$} & \multicolumn{10}{|c|}{ Factors affecting reputation } & \multirow{3}{*}{$\begin{array}{l}\begin{array}{c}\text { Global } \\
\text { assessment }\end{array} \\
\sum X_{i}\end{array}$} \\
\hline & \multicolumn{2}{|c|}{ Experience } & \multicolumn{2}{|c|}{ Role } & \multicolumn{2}{|c|}{ Cohesion } & \multicolumn{2}{|c|}{ Coupling } & \multicolumn{2}{|c|}{ Social impact } & \\
\hline & $\begin{array}{l}\text { Years, } \\
\text { diversity of } \\
\text { S\&T areas. } \\
\text { Publications } \\
\text { Impact } \\
\text { indexes }\end{array}$ & $\mathrm{X}_{1}$ & $\begin{array}{l}\text { Level of } \\
\text { responsibility } \\
\text { in the team } \\
\text { and project } \\
\text { (higher as IP) }\end{array}$ & $x_{2}$ & NA & $X_{3}$ & NA & $\mathrm{X}_{4}$ & $\begin{array}{l}\% \text { of people } \\
\text { knowing } \\
\text { his/her } \\
\text { activities } \\
\text { and } \\
\text { average of } \\
\text { external } \\
\text { opinions }\end{array}$ & $X_{5}$ & \\
\hline $\begin{array}{l}\text { Research } \\
\text { group }\end{array}$ & $\begin{array}{l}\text { Years of joint } \\
\text { work, } \\
\text { complexity of } \\
\text { projects. } \\
\text { Joint } \\
\text { publications }\end{array}$ & $Y_{1}$ & $\begin{array}{l}\text { Level and } \\
\text { diversity of } \\
\text { responsibilitie } \\
\text { s assumed by } \\
\text { the group in } \\
\text { the project } \\
\text { (i.e. WP } \\
\text { leader, task } \\
\text { leader) }\end{array}$ & $Y_{2}$ & $\begin{array}{l}\text { Size of } \\
\text { permane } \\
\text { nt staff } \\
\text { (higher if } \\
\text { all } \\
\text { members } \\
\text { are stable } \\
\text { staff) }\end{array}$ & $Y_{3}$ & $\begin{array}{l}\text { Joint } \\
\text { Participat } \\
\text { ion in R\&I } \\
\text { projects }\end{array}$ & $\mathrm{Y}_{4}$ & $\begin{array}{l}\text { \% of people } \\
\text { knowing } \\
\text { his/her } \\
\text { activities } \\
\text { and } \\
\text { average of } \\
\text { external } \\
\text { opinions }\end{array}$ & $Y_{5}$ & $\sum Y_{i}$ \\
\hline Node (firm) & $\begin{array}{l}\text { Years of } \\
\text { operation in } \\
\text { the interest } \\
\text { domain, } \\
\text { Complexity of } \\
\text { projects }\end{array}$ & $\mathrm{Z}_{1}$ & $\begin{array}{l}\text { Level and } \\
\text { diversity of } \\
\text { responsibilitie } \\
\text { s assumed by } \\
\text { the firm in the } \\
\text { project (i.e. } \\
\text { coordinator, } \\
\text { R\&D partner, } \\
\text { demonstrator } \\
\text {, etc.) }\end{array}$ & $\mathrm{Z}_{2}$ & & $Z_{3}$ & & $\mathrm{Z}_{4}$ & $\begin{array}{l}\text { \% of people } \\
\text { knowing } \\
\text { his/her } \\
\text { activities } \\
\text { and } \\
\text { average of } \\
\text { external } \\
\text { opinions }\end{array}$ & $Z_{5}$ & $\sum Z_{i}$ \\
\hline $\begin{array}{l}\text { Global } \\
\text { assessment }\end{array}$ & \multicolumn{2}{|l|}{$X_{1}+Y_{1}+Z_{1}$} & \multicolumn{2}{|l|}{$X_{2}+Y_{2}+Z_{2}$} & \multicolumn{2}{|l|}{$X_{3}+Y_{3}+Z_{3}$} & \multicolumn{2}{|l|}{$X_{4}+Y_{4}+Z_{4}$} & \multicolumn{2}{|l|}{$X_{5}+Y_{5}+Z_{5}$} & \\
\hline
\end{tabular}

Note: $\mathrm{X}$ ranges from 1 ( $\mathrm{min}$ ) to 5 (max). Values are allocated by the reputational evaluator team (must be external to the reputational object).

Table 3. Measurement criteria between factors and reputational levels (source: own elaboration)

In practice, an informal analysis of this type is always performed by responsible managers when a new R\&I project is launched, and people (internally) and external partners are needed to complete the necessary knowledge to conduct the project. Obviously, in practical cases, some constraints will reduce the searching process (e.g. in time, type of partners, and geographical space) and limit the possible range of individuals, research groups, and firms to be contacted and selected (in many cases, it is only an internal search in the firm).

Some funding agencies have defined specific tools to support proposers in this activity (e.g. the European Commission to find partners in the $\mathrm{H} 2020$ program ${ }^{16}$ ), but it only refers to quantitative data obtained from databases of participation (e.g. CORDIS ${ }^{17}$ ) and not on comprehensive reputational analysis. Then, they are usually complemented with opinions on the reputational

\footnotetext{
${ }^{16}$ https://ec.europa.eu/easme/en/section/horizon-2020-environment-and-resources/how-find-projectpartners

${ }^{17}$ CORDIS https://ec.europa.eu/info/funding-tenders/opportunities/portal/screen/how-toparticipate/partner-search
} 
object received from trustable people in relation of the network of contacts at individual or firm's levels (opinions that are not necessarily formalized).

\subsection{TRL CANVAS FOR THE PROJECT MANAGEMENT}

For the management and monitoring of the rigor of an R\&I project, a tool capable of showing the evolution of the project is necessary, as well as all the modifications during its execution. The "TRL Canvas" tool allows this management, since it combines the following characteristics:

- It allows to show the dimensions of product, process and researchers of the project, during all its development.

- It is an agile tool, which allows new by-products, researchers and activities to be incorporated, at any time.

- It allows assigning and deallocating researchers to the different activities of the project for each TRL level and by-products.

- It facilitates the calculation of the rigor of the project, both by TRL levels, as well as the dimensions of the product, process and researchers, by showing at all times all the elements of the project in a single matrix or canvas (its representation can also be done in format more typical of Canvas, with the activities assigned with post-its in the researchers' tables).

An example of the "TRL Canvas" matrix is shown below in Table 4.

\begin{tabular}{|c|c|c|c|c|c|c|c|c|c|}
\hline PROYECT X & TRL1 & TRL2 & TRL3 & TRL4 & TRL5 & TRL6 & TRL7 & TRL8 & TRL9 \\
\hline \multirow{3}{*}{ Researcher 1} & Activity 1 & & & & & & & & \\
\hline & Activity 2 & & & & & & & & \\
\hline & Activity 3 & & & & & & & & \\
\hline \multirow{3}{*}{ Researcher 2} & Activity 1 & & & & & & & & \\
\hline & Activity 2 & & & & & & & & \\
\hline & Activity 3 & & & & & & & & \\
\hline \multirow{3}{*}{ Researcher 3} & Activity 1 & & & & & & & & \\
\hline & Activity 2 & & & & & & & & \\
\hline & Activity 3 & & & & & & & & \\
\hline
\end{tabular}

Table 4. TRL Canvas template of an R\&I project (Source: own elaboration)

\subsection{D RIGOR METHOD}

To measure the rigor of an R\&I project using the "3D Rigor Method", it will be necessary to meet the following general considerations: 
1. The rigor of the project will be calculated based on the values of rigor of the product, process and researchers of the project.

2. The TRL level scale is used to assign the initial value of product rigor.

3. The set of initial activities for each level of TRL, obtained from the Technology Readiness Calculator tool, defines the initial value of process rigor.

4. The rigor value of researchers will be given as an inverse function of their reputation.

5. All the values of rigor of product, process and researchers may vary during the project, as new by-products, new activities by level and changes in the reputation of the researchers are added.

Taking into account the above considerations, the procedure for applying the 3D Rigor Method is as follows:

1. Establishment of initial values for the rigors of product, process and researchers.

a. If there is previous information on previous related projects, these values can be used as initials of the project, taking advantage of the accumulated knowledge of previous experiences.

b. If there is no previous information, the default values are used:

i. Product: rigor values associated with the nine levels of the TRL scale.

ii. Researchers: inverse of the reputation of researchers.

iii. Process: average of the rigor of the researchers who participate in the different activities from the Technology Readiness Calculator.

2. Configuration of the "TRL Canvas".

a. Include in each column of the matrix the nine levels of TRL, as well as by-products associated with each TRL if they are already known (for example, for TRL1).

b. Include in each row of the matrix the researchers who will participate in the project.

c. Include by TRL and in each box of each researcher the activities of that TRL level.

3. Development of the project, based on the established initial values and using the "TRL Canvas" for its management and monitoring.

4. Obtaining the results of the project.

a. Project summary, with the full detail of activities conducted, products and intermediate by-products obtained in each part, as well as the researchers who have participated in each activity and product throughout the project.

b. Final representation of the rigor values for the project.

i. Use of the TRL Radar diagram for graphic representation.

ii. A summary table of the values of rigor.

iii. The results obtained can be compared with the pre-established values to see deviations, necessary adjustments for future projects, etc.

Figure 5 shows an example of the result of the calculation of the rigor associated with an R\&I project using a TRL Radar diagram with the different values of product, process and researchers rigor for each TRL level. 


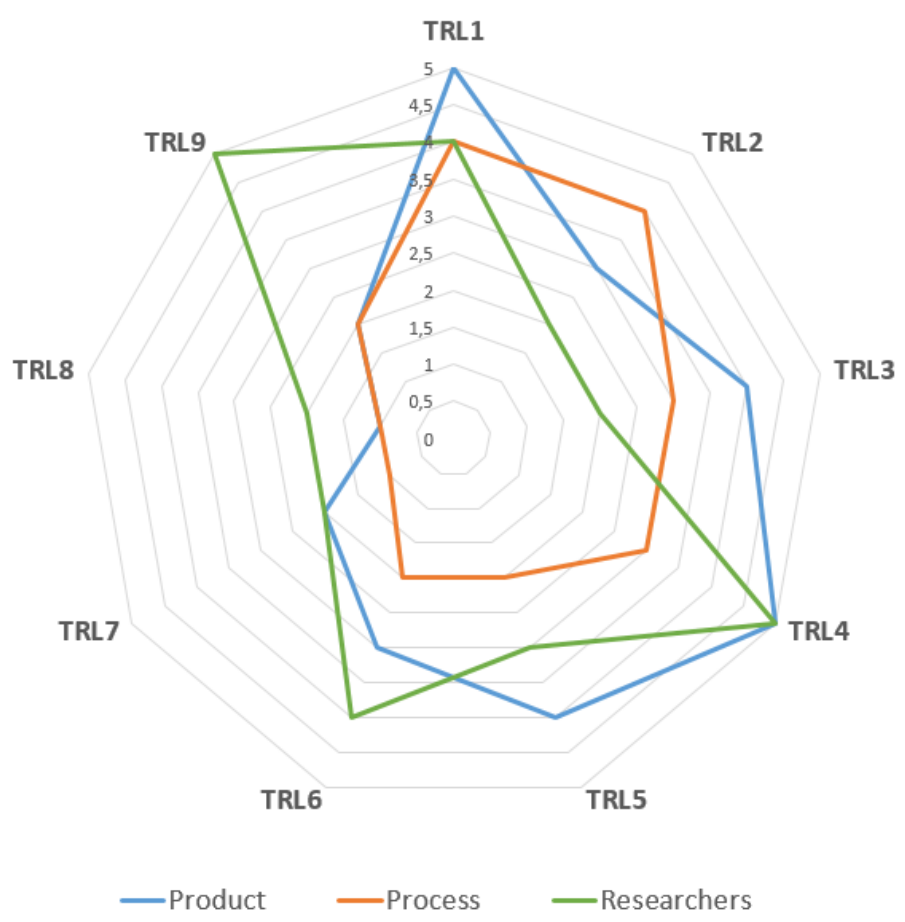

Figure 5. TRL Radar diagram for the representation of the rigor of an R\&I project (Source: own elaboration)

The TRL Radar diagram can also be used to track the evolution of the project rigor values throughout its development. Table 5 summarizes all the rigor values obtained in the R\&I project of the example represented in Figure 5.

\begin{tabular}{|c|c|c|c|c|c|c|c|c|c|c|}
\hline & TRL1 & TRL2 & TRL3 & TRL4 & TRL5 & TRL6 & TRL7 & TRL8 & TRL9 & $\begin{array}{c}\text { Project } \\
\text { Rigor }\end{array}$ \\
\hline Product & 5 & 3 & 4 & 5 & 4 & 3 & 2 & 1 & 2 & \\
\cline { 1 - 8 } Process & 4 & 4 & 3 & 3 & 2 & 2 & 1 & 1 & 2 & \multirow{2}{*}{2,96} \\
\hline Researchers & 4 & 2 & 2 & 5 & 3 & 4 & 2 & 2 & 5 & \\
\hline Totals TRLi & 4 & 3 & 3 & 4 & 3 & 3 & 2 & 1 & 3 & \\
\hline
\end{tabular}

Tabla 5. Summary of the rigor values of an R\&I project (Source: own elaboration)

\section{CONCLUSIONS}

New times make new approaches and tools necessary, which allow the adaptation and use of new opportunities. The management of R\&I projects, due to its high latent uncertainty, requires more flexible approaches, although without losing minimum levels of scientific rigor to ensure quality results. A feasible solution is presented in this document, focused on monitoring the development of the project and supported by well-known tools such as TRL.

R\&I projects are composed of researchers, who play a crucial role in the success of the projects. So much so that, the assessment of reputation levels became a key element to define management 
processes in R\&I projects where several people, research groups and entities participate together. It implies a multifaceted analysis based on reliable data, opinions and part performance, which should be updated periodically. An open issue is to combine this reputation process assessment with other management processes to increase the confidence in the success of R\&I projects.

\section{REFERENCES}

[1] EASTERBY-SMITH, Mark; THORPE, Richard; JACKSON, Paul R. Management research. Sage, 2012.

[2] CHESBROUGH, Henry William. Open innovation: The new imperative for creating and profiting from technology. Harvard Business Press, 2003.

[3] ROTHWELL, Roy. Successful industrial innovation: critical factors for the 1990s. R\&d Management, 1992, vol. 22, no 3, p. 221-240.

[4] JALONEN, Harri; LEHTONEN, Annina. Uncertainty in the innovation process. En European Conference on Innovation and Entrepreneurship. Academic Conferences International Limited, 2011. p. 51.

[5] ESCORSA CASTELLS, Pere; PASOLA, Jaume Valls. Tecnología e innovación en la empresa (Vol. 148): Univ. Politèc. de Catalunya, 2003.

[6] HOBDAY, Michael. Firm-level innovation models: perspectives on research in developed and developing countries. Technology analysis \& strategic management, 2005, vol. 17, no 2, p. 121-146.

[7] FORREST, Janet F. Practitioners' forum: Models of the process technological innovation. Technology Analysis \& Strategic Management, 1991, vol. 3, no 4, p. 439-453.

[8] CASTILLO, Edelmira; VÁSQUEZ, Martha Lucia. El rigor metodológico en la investigación cualitativa. Colombia médica, 2003, vol. 34, no 3, p. 164-167.

[9] SCHUETZENMEISTER, Falk. University research management: An exploratory literature review. 2010.

[10] TAUGINIENÉ, Loreta. The roles of a research administrator at a university. Public Policy and Administration, 2009, vol. 1, no 30, p. 45-56.

[11] HOLM, Johann Erich Wolfgang; VAN DER MERWE, G. P. R. Quality Research Management Improves Design Research Effectiveness. South African Journal of Industrial Engineering, 2019, vol. 30 , no 3, p. 238-252.

[12] HUANG, Jun Song; HUNG, David. Building the science of research management-What can research management learn from education research?. 2018.

[13] MOROTE, Julián Pavón; SERRANO, Gonzalo León; NUCHERA, Antonio Hidalgo. La gestión de la innovación y la tecnología en las organizaciones. Ediciones Pirámide, 2014. 
[14] EVELEENS, Chris. Innovation management; a literature review of innovation process models and their implications. Science, 2010, vol. 800, no 2010, p. 900-916.

[15] LUNDVALL, Bengt-Åke. Innovation studies: A personal interpretation of the state of the art. Innovation studies: evolution and future challenges, 2013, vol. 21.

[16] ALLENDE, Jorge E. Rigor: The essence of scientific work. Electronic Journal of Biotechnology, 2004, vol. 7, no 1, p. 0-0.

[17] MANKINS, John C. Technology readiness assessments: A retrospective. Acta Astronautica, 2009, vol. 65, no 9-10, p. 1216-1223.

[18] MANKINS, John C. Technology readiness levels. White Paper, April, 1995, vol. 6, p. 1995.

[19] TOBERGTE, D. R.; CURTIS, S. Niveles de madurez de la tecnologia. Technology Readiness Levels. TRLS. Una Introducción. Journal of Chemical Information and Modeling, 2013, vol. 53, no 9, p. 1689-1699.

[20] RIES, Eric. Minimum viable product: a guide. Startup lessons learned, 2009.

[21] LEÓN, Gonzalo, et al. Proximity Metrics for Selecting R\&D Partners in International Open Innovation Processes. IEEE Access, 2019, vol. 7, p. 79737-79757.

[22] KJELLBERG, Sara; HAIDER, Jutta. Researchers' online visibility: Tensions of visibility, trust and reputation. Online information review, 2019.

[23] DUFFY, Brooke Erin; POOLEY, Jefferson D. "Facebook for academics": the convergence of selfbranding and social media logic on Academia. edu. Social media+ society, 2017, vol. 3, no 1, p. 2056305117696523.

[24] CERVI, Cristiano R.; GALANTE, Renata; DE OLIVEIRA, José Palazzo M. Comparing the reputation of researchers using a profile model and scientific metrics. En 2013 IEEE 16th International Conference on Computational Science and Engineering. IEEE, 2013. p. 353-359. 